\title{
Risk factors of incisional hernia after single-incision cholecystectomy and safety of barbed suture material for wound closure
}

\author{
Yeseul Kim¹, Sunghoon Choi', Sungyub Jeong², Sunghwan Lee¹, Incheon Kang ${ }^{1}$, Jaeyoung Jang \\ ${ }^{1}$ Division of Hepatobiliary and Pancreas, Department of Surgery, CHA Bundang Medical Center, Seongnam, Korea \\ 2Department of Surgery, Armed Force Capital Hospital, Seongnam, Korea
}

Purpose: Single-incision cholecystectomy is a surgical method that offers comparable results to conventional laparoscopic cholecystectomy. However, a high risk of postoperative incisional hernia is an issue in single-incision cholecystectomy. This study evaluated the risk factors and incidences of incisional hernia after single-incision cholecystectomy and the advantage issue of using barbed suture material during wound closures.

Methods: A total of 1,111 patients underwent laparoscopic or robotic single-incision cholecystectomy between March 2014 and February 2020 at our institution at CHA Bundang Medical Center. During this period, there were 693 patients who underwent wound closure with monofilament suture material (Monosyn 2-0; B. Braun) and the other 418 patients used barbed suture material (Stratafix 2-0; Ethicon).

Results: The two patient groups were comparable in age, body mass index, and diagnosis. The total incidence of incisional hernia after single-incision cholecystectomy was $0.5 \%$ (five cases). All patients who developed incisional hernia were in the monofilament suture material group $(0.7 \%$ vs. $0 \%, p=0.021)$. The influence of predictive and possible risk factors on incisional hernia rate was analyzed. Among these factors, only old age was an independent predictive risk factor of incisional hernia.

Conclusion: Our study showed a low incidence of incisional hernia, all of which occurred in the monofilament suture material group. If technically appropriate, single-incision cholecystectomy does not appear to present a high incidence of hernia. Barbed suture material can be safely applied in wound closure showing comparable incisional hernia incidence to monofilament suture material.

Keywords: Incisional hernia, Laparoscopy, Cholecystectomy, Minimally invasive surgery

This is an Open Access article distributed under the terms of the Creative Commons Attribution Non-Commercial License (http:// creativecommons.org/licenses/by-nc/4.0/) which permits unrestricted non-commercial use, distribution, and reproduction in any medium, provided the original work is properly cited.
Received May 17, 2021

Revised 1st July 12,2021 2nd August 17,2021 3rd August 23, 2021 4th August 31, 2021 5th September 8, 2021 6th September 11,2021 7th September 12, 2021

Accepted September 13, 2021

Corresponding author Sunghoon Choi Division of Hepatobiliary and Pancreas, Department of Surgery, CHA Bundang Medical Center, CHA University, 59 Yatap-ro, Bundang-gu, Seongnam 13496, Korea Tel: $+82-31-780-1824$

Fax: +82-31-780-5259

E-mail: feel415@cha.ac.kr ORCID:

https://orcid.org/0000-0002-2102-7216
Copyright $\odot$ The Korean Society of Endoscopic and Laparoscopic Surgeons.

\section{INTRODUCTION}

Conventional laparoscopic cholecystectomy (CLC) with a fourport technique has become the gold standard for management of symptomatic gallbladder disease [1]. To minimize surgical wounds, single-incision surgery including cholecystectomy has been increasing. Single-incision surgery has benefits of fewer surgical wounds that allow faster recovery by reducing surgical stress and pain, leading to better cosmesis [2]. Despite these advantages, single-incision cholecystectomy has no advantages in operation time, the average length of stay in a hospital, return to normal activities, or postoperative quality of life compared to CLC $[3,4]$.

A recent meta-analysis by Haueter et al. [5] found that single- 
incision laparoscopic cholecystectomy (SILC) has advantages in cosmesis, body image, and postoperative pain compared with CLC, but the incidence of incisional hernia is higher. SILC and robotic single-site cholecystectomy require a larger fascia incision at the umbilicus than that in CLC, increasing the possibility of incisional hernia [6,7]. It is important that single-incision cholecystectomy has a cosmetic advantage over CLC; however, incisional hernia is not only a cosmetic issue but also can cause intestinal obstruction and ischemia, leading to a potentially lifethreatening condition that could necessitate emergency surgery [8].

Surgical technique failures such as suture material loosening, or breakage of a surgical knot can result in incisional hernia. Single-site cholecystectomy requires a larger fascia incision than CLC, and there is a greater possibility of surgical failure. Barbed suture materials, which were patented in 1964, are growing in popularity [9]. They have been reintroduced for several surgical applications such as digestive surgery $[10,11]$ and fascia closure $[12,13]$. We hypothesized that barbed suture materials can help prevent these surgical failures and using reduce the incidence of incisional hernia. This study evaluated the incidence of incisional hernia after single-incision cholecystectomy, the influence of risk factors on incisional hernia rate, and demonstrated the safety of barbed suture materials for fascia closure.

\section{METHODS}

\section{Patients and study design}

A total of 1,111 patients underwent laparoscopic or robotic singleincision cholecystectomy between March 2014 and February 2020 by three surgeons in CHA Bundang Medical Center. We analyzed the data for 693 patients who underwent wound closure with monofilament suture material (Monosyn 2-0; B. Braun, Melsungen, Germany) and 418 patients with barbed suture material (Stratafix 2-0; Ethicon, Raritan, NJ, USA).

Demographic variables, operative parameters, and postoperative outcome data were obtained and evaluated from a prospective database with additional retrospective medical record review and patient contact. Operation time was dichotomized according to the median ( 47.3 minutes), old age was defined over 60 years, and obesity was defined as body mass index (BMI) of $>25 \mathrm{~kg} / \mathrm{m}^{2}$. American Society of Anesthesiologists (ASA) physical status (PS) classification was divided as I and $\geq$ II. A postoperative complication was defined as any complication of Clavien-Dindo classification $\geq$ II during the follow-up period $[14,15]$. Postoperatively, patients visited the outpatient clinic at 1 week and 1 month following the procedure. After that, patients who complained of a bulging at the umbilicus were reexamined at the outpatient clinic, and abdomen-pelvis computed tomography was performed when required.

\section{Surgical procedure}

Because of the three surgeons in our hepatobiliary division, we standardize the procedure which is as follows.

We used Gloveport (Nelis, Bucheon, Korea) with four channels for all single-incision cholecystectomy procedures. A 2.5$\mathrm{cm}$ vertical transumbilical skin incision was made, the fascia was opened about $3 \mathrm{~cm}$, and the glove port was installed. Then, a laparoscopic instrument was inserted, or the robotic arm was docked, and cholecystectomy was conducted. At the end of surgery, fascia closure was achieved with running sutures of monofilament suture material (Monosyn 2-0) or barbed suture material (Stratafix 2-0) with each bite of 5-mm interval.

\section{Statistical methods}

Statistical analysis was performed using $\mathrm{R}$ version $\mathrm{R}$ 4.0.0 ( $\mathrm{R}$ Foundation for Statistical Computing, Vienna, Austria). Categorical variables were compared with the chi-square or Fisher exact test. Equality of variances in continuous variables was tested by the Levene test. Continuous variables with symmetrical distribution were compared using the independent $t$ test. Continuous data with asymmetrical distribution were compared using Mann-Whitney $U$ test. As for risk analysis of incisional hernia, logistic regression was performed. Two-tailed analyses were performed, and a $p$ value of $<0.05$ was considered significant.

\section{RESULTS}

\section{Demographics of patient and perioperative outcomes}

There were differences in sex (female rate for monofilament vs. barbed, $65.7 \%$ vs. $56.9 \%$; $p=0.004)$ and ASA PS classification (classification I rate for monofilament vs. barbed, $61.5 \%$ vs. $45.7 \%$; $p \leq 0.001)$ in the two groups. Age $(45.8 \pm 13.1$ years vs. $47.1 \pm 12.5$ years, $p=0.119)$, BMI $\left(24.4 \pm 3.7 \mathrm{~kg} / \mathrm{m}^{2}\right.$ vs. $24.6 \pm 3.6 \mathrm{~kg} / \mathrm{m}^{2}, p=$ $0.369)$, and previous surgical history ( $23.2 \%$ vs. $23.9 \%, p=0.374)$ were comparable in the monofilament vs. barbed groups, as was acute cholecystitis rate $(11.0 \%$ vs. $11.5 \%, p=0.812)$ (Table 1 ).

The total incidence of incisional hernia after single-incision cholecystectomy was $0.5 \%$ (5 of 1,111 patients). All patients who developed incisional hernia were in the monofilament suture material group. Total operation time was slightly longer in the barbed suture material group ( $46.5 \pm 15.2$ minutes vs. $48.6 \pm 17.3$ minutes, $p=0.045$ ), intraoperative bile spillage rate was higher in the barbed suture material group (15.9\% vs. $25.4 \%, p \leq 0.001)$, while total complication rate was higher in the monofilament suture material group $(2.9 \%$ vs. $0.5 \%, p=0.010)$ (Table 1$)$. 
Table 1. Patients' demographics and perioperative outcomes

\begin{tabular}{|c|c|c|c|}
\hline Variable & $\begin{array}{l}\text { Monofilament } \\
\text { suture } \\
\text { material } \\
\text { group }\end{array}$ & $\begin{array}{l}\text { Barbed } \\
\text { suture } \\
\text { material } \\
\text { group }\end{array}$ & $p$ value \\
\hline No. of patients & 693 & 418 & \\
\hline $\begin{array}{l}\text { Sex } \\
\text { Male } \\
\text { Female }\end{array}$ & $\begin{array}{l}238(34.3) \\
455(65.7)\end{array}$ & $\begin{array}{l}180(43.1) \\
238(56.9)\end{array}$ & $0.004^{*}$ \\
\hline Age (yr) & $45.8 \pm 13.1$ & $47.1 \pm 12.5$ & 0.119 \\
\hline Body mass index $\left(\mathrm{kg} / \mathrm{m}^{2}\right)$ & $24.4 \pm 3.7$ & $24.6 \pm 3.6$ & 0.369 \\
\hline $\begin{array}{l}\text { ASA PS classsification } \\
\text { | } \\
\| \\
\|\|\end{array}$ & $\begin{array}{c}426(61.5) \\
256(36.9) \\
11(1.6)\end{array}$ & $\begin{array}{c}191(45.7) \\
217(51.9) \\
10(2.4)\end{array}$ & $<0.001^{*}$ \\
\hline $\begin{array}{l}\text { Previous surgery history } \\
\text { No } \\
\text { Yes }\end{array}$ & $\begin{array}{l}532(76.8) \\
161(23.2)\end{array}$ & $\begin{array}{l}318(76.1) \\
100(23.9)\end{array}$ & $0.374^{*}$ \\
\hline $\begin{array}{l}\text { Diagnosis } \\
\text { Chronic cholecystitis } \\
\text { Gallbladder polyp } \\
\text { Acute cholecystitis }\end{array}$ & $\begin{array}{l}587(84.7) \\
30(4.3) \\
76(11.0)\end{array}$ & $\begin{array}{l}355(84.9) \\
15(3.6) \\
48(11.5)\end{array}$ & 0.812 \\
\hline Operation time (min) & $46.5 \pm 15.2$ & $48.6 \pm 17.3$ & $0.045^{\star}$ \\
\hline $\begin{array}{l}\text { Bile spillage } \\
\text { No } \\
\text { Yes }\end{array}$ & $\begin{array}{l}583(84.1) \\
110(15.9)\end{array}$ & $\begin{array}{l}312(74.6) \\
106(25.4)\end{array}$ & $<0.001^{*}$ \\
\hline Postoperative complication & $20(2.9)$ & $2(0.5)$ & $0.010^{*}$ \\
\hline $\begin{array}{l}\text { Complication type related to SS } \\
\text { Incisional hernia } \\
\text { Wound infection }\end{array}$ & $\begin{array}{l}5(0.7) \\
0(0)\end{array}$ & $\begin{array}{l}0(0) \\
1(0.2)\end{array}$ & $0.021^{*}$ \\
\hline
\end{tabular}

Values are presented as number (\%) or mean \pm standard deviation.

ASA, American Society of Anesthesiologists; PS, physical status; SS, surgical site.

${ }^{*} p<0.05$.

Postoperative complications included persistent abdominal pain after postoperative day 7 (seven cases), severe constipation (four cases), postoperative ileus (five cases), incisional hernia (five cases), and wound infection (one case).

\section{Influence of perioperative factors on incisional hernia rate}

The influence of perioperative factors on incisional hernia is reported in Table 2. Incidence of incisional hernia was observed higher in females $(0.6 \%)$, those with a BMI less than $25 \mathrm{~kg} / \mathrm{m}^{2}$ $(0.5 \%)$; however, there was no statistical significance. The patients
Table 2. Preoperative characteristics of the patients with and without incisional hernia

\begin{tabular}{|c|c|c|c|}
\hline Variable & $\begin{array}{c}\text { No incisional } \\
\text { hernia }\end{array}$ & $\begin{array}{l}\text { Incisional } \\
\text { hernia }\end{array}$ & $p$ value \\
\hline Sex & & & 0.724 \\
\hline Male & 417 (99.8) & $1(0.2)$ & \\
\hline Female & $689(99.4)$ & $4(0.6)$ & \\
\hline Age (yr) & & & $\leq 0.001^{*}$ \\
\hline$\leq 60$ & 953 (99.9) & $1(0.1)$ & \\
\hline$>60$ & $153(97.5)$ & $4(2.5)$ & \\
\hline $\mathrm{BMI}\left(\mathrm{kg} / \mathrm{m}^{2}\right)$ & & & $>0.999$ \\
\hline$\leq 25$ & 681 (99.6) & $3(0.4)$ & \\
\hline$>25$ & 425 (99.5) & $2(0.5)$ & \\
\hline ASA PS classification & & & $0.040^{*}$ \\
\hline 1 & 617 (100) & $0(0)$ & \\
\hline$\geq \|$ & 489 (99.0) & $5(1.0)$ & \\
\hline No. of risk factors ${ }^{a)}$ & & & $0.001^{*}$ \\
\hline 0 & $111(100)$ & $0(0)$ & \\
\hline 1 & 435 (100) & $0(0)$ & \\
\hline 2 & $382(99.7)$ & $1(0.3)$ & \\
\hline$\geq 3$ & 178 (97.8) & $4(2.2)$ & \\
\hline
\end{tabular}

Values are presented as number (\%).

BMI, body mass index; ASA, American Society of Anesthesiologists; PS, physical status.

a) If the patient is over 60 years old, BMl higher than $25 \mathrm{~kg} / \mathrm{m}^{2}$, or ASA PS classification higher than I, we count each of variables as a risk factor. ${ }^{*} p<0.05$.

older than 60 years $(2.6 \%, p \leq 0.001)$ and those with ASA PS classification lower than II $(1.0 \%, p=0.040)$ showed a significantly higher incidence of incisional hernia. The influence of additional factors related to disease and operation on the incisional hernia are reported in Table 3. Higher incidences of incisional hernia were observed in patients with acute cholecystitis (1.6\%), intraoperative bile spillage (0.5\%), and longer operation time (1.0\%) and with the use of monofilament suture material (0.7\%); however, there was no statistical significance. For logistic regression, we selected variables such as sex, age, and BMI which were wellknown patients' risk factors of incisional hernia [16]. In addition, disease and operation-related factors that might affect incidence of incisional hernia such as diagnosis of acute cholecystitis, bile spillage during operation, and long operation time were also included in the analysis [17]. Multiple logistic regression analysis also yielded similar results, showing that age was positively associated incisional hernia (odds ratio [OR], 27.35; 95\% confidence interval [CI], 3.67-567.82; $p=0.004$ ) (Table 4). 
Table 3. Operative characteristics of the patients with and without incisional hernia

\begin{tabular}{llll}
\hline \multicolumn{1}{c}{ Variable } & $\begin{array}{c}\text { No incisional } \\
\text { hernia }\end{array}$ & $\begin{array}{c}\text { Incisional } \\
\text { hernia }\end{array}$ & $p$ value \\
\hline $\begin{array}{c}\text { Acute cholecystitis } \\
\text { Yes }\end{array}$ & $122(98.4)$ & $2(1.6)$ & 0.180 \\
No & $984(99.7)$ & $3(0.3)$ & \\
Bile spillage & & & $>0.999$ \\
Yes & $215(99.5)$ & $1(0.5)$ & \\
No & $891(99.6)$ & $4(0.45)$ & \\
Operation time (min) & & & 0.125 \\
$\leq 47.3$ & $699(99.9)$ & $1(0.1)$ & \\
$>47.3$ & $407(99.0)$ & $4(1.0)$ & \\
Suture material & & & 0.201 \\
Monofilament & $688(99.3)$ & $5(0.7)$ & \\
Barbed & $418(100)$ & $0(0)$ & \\
No. of risk factors ${ }^{\text {a) }}$ & & & \\
0 & $189(100)$ & $0(0)$ & \\
1 & $530(99.8)$ & $1(0.2)$ & \\
2 & $272(99.3)$ & $2(0.7)$ & \\
$\geq 3$ & $115(98.3)$ & $2(1.7)$ & \\
\hline
\end{tabular}

Values are presented as number (\%).

a) If the patient had acute cholecystitis, bile spillage occurred during operation, longer operation time than 47.3 minutes, or suture material with monofilament, we count each of variables as a risk factor.

${ }^{\star} p<0.05$.

\section{DISCUSSION}

Incisional hernia after laparoscopic surgery has been researched in many institutions. Recently, several systematic reviews and meta-analyses of randomized clinical trials comparing single-incision cholecystectomy and CLC have been published. SILC was associated with a better cosmetic result but a higher incisional hernia rate [16]. Previously reported incidences of incisional hernia after CLC and SILC occur across a broad range. Nassar et al. [18] reported that incisional hernia rate after CLC was $1.8 \%$ over a follow-up duration of up to 18 months. In a more recent randomized prospective trial with a 12-month follow-up, the incisional hernia rate after CLC was 1.2\% [19]. Gangl et al. [20] observed incisional hernia after SILC in 53 cases with complete follow-up, an incisional hernia rate of 1.9\%, like that of CLC. Marks et al. [19] reported a much higher incisional hernia rate of $8.4 \%$ for SILC patients. In our study, the overall postoperative incisional hernia rate was $0.5 \%$, much lower than that previously reported after SILC and ever lower than that of CLC.

Previous studies have shown several risk factors of incisional hernia. In a review of the literature on incisional hernia after
Table 4. Analysis of risk factors related to incisional hernia

\begin{tabular}{|c|c|c|c|c|}
\hline \multirow[b]{2}{*}{ Variable } & \multicolumn{2}{|c|}{ Univariable } & \multicolumn{2}{|c|}{ Multivariable } \\
\hline & $\begin{array}{c}\text { OR } \\
(95 \% \text { Cl) }\end{array}$ & $p$ value & $\begin{array}{c}\text { OR } \\
(95 \% \text { Cl) }\end{array}$ & $p$ value \\
\hline \multicolumn{5}{|l|}{ Sex } \\
\hline Male & 1.0 & & 1.0 & \\
\hline Female & $\begin{array}{c}2.42 \\
(0.35-47.44)\end{array}$ & 0.437 & $\begin{array}{c}3.96 \\
(0.51-84.94)\end{array}$ & 0.246 \\
\hline \multicolumn{5}{|l|}{ Age (yr) } \\
\hline$\leq 60$ & 1.0 & & 1.0 & \\
\hline$>60$ & $\begin{array}{c}24.30 \\
(3.56-477.13)\end{array}$ & $0.002^{*}$ & $\begin{array}{c}27.35 \\
(3.67-567.82)\end{array}$ & $0.004^{*}$ \\
\hline \multicolumn{5}{|l|}{$\mathrm{BMl}\left(\mathrm{kg} / \mathrm{m}^{2}\right)$} \\
\hline$\leq 25$ & 1.0 & & 1.0 & \\
\hline$>25$ & $\begin{array}{c}1.07 \\
(0.14-6.47)\end{array}$ & 0.943 & $\begin{array}{c}1.10 \\
(0.13-7.32)\end{array}$ & 0.924 \\
\hline \multicolumn{5}{|l|}{ Diagnosis } \\
\hline Others & 1.0 & & 1.0 & \\
\hline Acute cholecystitis & $\begin{array}{c}5.37 \\
(0.44-47.26)\end{array}$ & 0.098 & $\begin{array}{c}5.68 \\
(0.62-48.70)\end{array}$ & 0.100 \\
\hline
\end{tabular}

Bile spillage

$\begin{array}{ccccc}\text { No } & 1.0 & & 1.0 & \\ \text { Yes } & 1.04 & 0.972 & 4.12 & 0.262 \\ & (0.05-7.05) & & (0.47-96.89) & \end{array}$

\begin{tabular}{|c|c|c|c|c|}
\hline \multicolumn{5}{|c|}{ Operation time (min) } \\
\hline$\leq 47.3$ & 1.0 & & 1.0 & \\
\hline$>47.3$ & $\begin{array}{c}6.87 \\
(1.01-134.60)\end{array}$ & 0.085 & $\begin{array}{c}5.10 \\
(0.63-106.25)\end{array}$ & 0.168 \\
\hline
\end{tabular}

$\mathrm{OR}$, odds ratio; $\mathrm{Cl}$, confidence interval; $\mathrm{BMI}$, body mass index. ${ }^{*} p<0.05$.

CLC, it has been suggested that old age, high BMI, and long operation time increase the risk of incisional hernia [21]. Erdas et al. [22] reported variables related to incisional hernia over a mean follow-up period of 89 months, noted that obesity and gallstones larger than $2 \mathrm{~cm}$ were significantly associated with the increased rate. Another study reported that elevated BMI, preexisting umbilical hernia, old age, high ASA PS classification, and sex were risk factors for incisional hernia after single-incision cholecystectomy [23]. According to a comprehensive literature review, the predictive risk factors of incisional hernia after single-incision cholecystectomy were sex, old age, high BMI, high ASA PS classification, and long operation time. Incidence of incisional hernia was observed in patients with the age older than 60 years $(2.6 \%$, $p \leq 0.001)$, high BMI over $25 \mathrm{~kg} / \mathrm{m}^{2}(0.5 \%, p>0.999)$, and ASA 
PS classification of $\geq \mathrm{II}(1.0 \%, p=0.040)$. Next, we investigated whether there is a greater probability of developing incisional hernia with increased number of the preoperative patients' risk factors (sex, old age, high BMI, and high ASA PS classification). Statistical analysis showed that having a greater number of those risk factors was associated with a higher incidence of incisional hernia as seen in (Table 2).

Other studies have reported additional possible risk factors of incisional hernia. Patients with acute cholecystitis and intraoperative bile spillage tended to be more affected by wound infection, which can lead to incisional hernia [24]. Long operation time could modify the trocar site abdominal wall structure, increasing the possibility of incisional hernia [13]. In addition, incisional hernia developed only in the monofilament suture material group in our study.

Considering the additional risk factors related to disease and operation (acute cholecystitis, bile spillage during operation, and long operation time), the incidence of incisional hernia was $0.2 \%$ in patients with one factor, $0.7 \%$ in patients with two factors, and up to $1.7 \%$ in patients with three or more risk factors $(p=0.002)$, implying that the more risk factors the patients have, the more possibility of developing incisional hernia the patients might get (Table 3). Among the variables of sex, age, acute cholecystitis, bile spillage during operation, and operation time, only old age was revealed as an independent risk factor of incisional hernia (OR, 27.35; 95\% CI, 3.67-567.82; $p=0.004$ ) in the multiple logistic analysis. Regarding ASA PS classification, there was no one with $\geq \mathrm{III}$ in the patients who developed incisional hernia. In general, clinical difference between ASA PS classification I designating normal healthy status and ASA PS classification II designating mild diseases without substantive functional limitations is not regarded as significant; and univariable analysis could not calculate OR even when we dichotomized ASA PS classification to I and $\geq$ II. When conducting risk factor analysis using logistic regression, therefore, we decided not to include ASA PS classification as a variable.

Extending the camera port site to facilitate extraction of the gallbladder was a previous important predictive factor of incisional hernia after CLC [21]. Single-site cholecystectomy usually requires a larger fascia incision than CLC and is regarded as a higher risk for incisional hernia. Although, Krajinovic et al. [6] mentioned, creating a larger incision of the fascia gives the operator has better control of the abdominal wall layers during closure. It may also cause a higher risk of developing incisional hernia. Therefore, surgical failures such as suture material loosening or breakage in the surgical knot are important risk factors of incisional hernia.

Barbed suture materials have a unique characteristic in that they allow easier closure of the abdominal fascia because of their own one-way direction. In addition, use of a loop-style surgical knot or stanchion at the starting point eliminates the need to create a surgical knot during fascia closure. For these reasons, barbed suture materials can be safely applied for fascia closure after single-incision cholecystectomy, with minimized surgical failures and a lower risk of incisional hernia. Surprisingly, there was no case of incisional hernia after single-incision cholecystectomy in the barbed suture material group, despite the presence of a larger number of predictive or possible risk factors including older age, which was the only independent risk factor of incisional hernia in our study. Therefore, barbed suture materials can be a reasonable option for fascia closure after single-site cholecystectomy to reduce the likelihood of incisional hernia.

There are several limitations of our study. First, this study had a retrospective design. Second, the postoperative follow-up period was relatively short compared to previous studies. According to one previous report, to confirm the precise risk of postoperative incisional hernia, the duration of follow-up should be extended to 3 years [25]. In our study, postoperative routine outpatient clinic follow-up was set at postoperative day 7 and 30 . At that time, postoperative follow-up was terminated if there were no complications. If the patient had problems after postoperative 30 days, they visited until their symptoms such as steatorrhea, surgical wound pain, and dyspepsia became tolerable.

As a result, our median follow-up period was $24.8 \pm 7.8$ months in the monofilament suture material group and $12.2 \pm 5.2$ months in the barbed suture material group. With a longer follow-up period, more patients might have been experienced incisional hernia. Thus, there is a possibility of underestimated incidence of incisional hernia in our study. However, two-thirds of postoperative incisional hernia typically are diagnosed within 1 year after surgery [25]. Similarly, all incisional hernia patients were diagnosed within 1 year after surgery in our study. Though our incisional hernia incidence of about $0.5 \%$ was limited, considering a median follow-up period longer than 1 year in both groups, it was not likely much underestimated. Based on the literature, our adjusted incisional hernia rate is $0.7 \%$. The third limitation is that choice of suture material was not randomly selected. Despite these limitations, this single-center, large-volume study is the first that compared incisional hernia rate based on suture materials.

The incisional hernia rate after single-incision cholecystectomy was lower here than in previous studies. The only independent risk factor of incisional hernia was old age. Fascia closure with barbed suture material demonstrated no further increase of incisional hernia incidence compared to fascia closure with monofilament suture material in this study. Therefore, barbed suture material can be safely applied as an alternate suture material for wound closure after SILC. 


\section{NOTES}

\section{Ethical statements}

This study was approved by the Institutional Review Board and Ethics Committees of CHA Bundang Medical Center with the waiver of the informed consent (No. 2020-06-041). This study was conducted according to the principles of the Declaration of Helsinki.

\section{Authors' contributions}

Conceptualization: YK, SJ, SC

Data curation: YK, SJ, SL

Formal analysis: YK, SJ, SL

Funding acquisition: SJ, IK, JJ

Investigation: $\mathrm{YK}, \mathrm{SJ}$

Methodology: SC

Project administration: SC, SL

Visualization: YK, SJ

Writing-original draft: YK, SJ

Writing-review \& editing: YK

All authors read and approved the final manuscript.

\section{Conflict of interest}

All authors have no conflicts of interest to declare.

\section{Funding/support}

None.

\section{ORCID}

Yeseul Kim, https://orcid.org/0000-0001-5610-3357

Sunghoon Choi, https://orcid.org/0000-0002-2102-7216

Sungyub Jeong, https://orcid.org/0000-0003-1723-1465

Sunghwan Lee, https://orcid.org/0000-0003-3365-0096

Incheon Kang, https://orcid.org/0000-0003-4236-5094

Jaeyoung Jang, https://orcid.org/0000-0001-6139-1859

\section{REFERENCES}

1. Soper NJ, Stockmann PT, Dunnegan DL, Ashley SW. Laparoscopic cholecystectomy. The new 'gold standard'? Arch Surg 1992;127:917923.

2. Evers L, Bouvy N, Branje D, Peeters A. Single-incision laparoscopic cholecystectomy versus conventional four-port laparoscopic cholecystectomy: a systematic review and meta-analysis. Surg Endosc 2017;31:3437-3448
3. Buemi A, Swaelens C, Gherardi D, Malvaux P, Landenne J, Hauters P. Comparison between single incision and conventional laparoscopic cholecystectomy for uncomplicated cholelithiasis. Acta Chir Belg 2013;113:391-396.

4. Hauters P, Auvray S, Cardin JL, et al. Comparison between singleincision and conventional laparoscopic cholecystectomy: a prospective trial of the Club Coelio. Surg Endosc 2013;27:1689-1694.

5. Haueter R, Schütz T, Raptis DA, Clavien PA, Zuber M. Meta-analysis of single-port versus conventional laparoscopic cholecystectomy comparing body image and cosmesis. Br J Surg 2017;104:1141-1159.

6. Krajinovic K, Koeberlein C, Germer CT, Reibetanz J. The incidence of trocar site hernia after single-port laparoscopic cholecystectomy-a single center analysis and literature review. J Laparoendosc Adv Surg Tech A 2016;26:536-539.

7. Buckley FP 3rd, Vassaur HE, Jupiter DC, Crosby JH, Wheeless CJ, Vassaur JL. Influencing factors for port-site hernias after singleincision laparoscopy. Hernia 2016;20:729-733.

8. Swank HA, Mulder IM, la Chapelle CF, Reitsma JB, Lange JF, Bemelman WA. Systematic review of trocar-site hernia. Br J Surg 2012;99:315-323

9. Villa MT, White LE, Alam M, Yoo SS, Walton RL. Barbed sutures: a review of the literature. Plast Reconstr Surg 2008;121:102e-108e.

10. Nemecek E, Negrin L, Beran C, Nemecek R, Hollinsky C. The application of the V-Loc closure device for gastrointestinal sutures: a preliminary study. Surg Endosc 2013;27:3830-3834.

11. Facy O, De Blasi V, Goergen M, Arru L, De Magistris L, Azagra JS. Laparoscopic gastrointestinal anastomoses using knotless barbed sutures are safe and reproducible: a single-center experience with 201 patients. Surg Endosc 2013;27:3841-3845.

12. Bellón JM, Pérez-López P, Simón-Allue R, et al. New suture materials for midline laparotomy closure: an experimental study. BMC Surg 2014;14:70.

13. Oni G, Brown SA, Kenkel JM. A comparison between barbed and nonbarbed absorbable suture for fascial closure in a porcine model. Plast Reconstr Surg 2012;130:535e-540e.

14. Strasberg SM, Linehan DC, Hawkins WG. The accordion severity grading system of surgical complications. Ann Surg 2009;250:177-186.

15. Clavien PA, Barkun J, de Oliveira ML, et al. The Clavien-Dindo classification of surgical complications: five-year experience. Ann Surg 2009;250:187-196

16. Julliard O, Hauters P, Possoz J, Malvaux P, Landenne J, Gherardi D. Incisional hernia after single-incision laparoscopic cholecystectomy: incidence and predictive factors. Surg Endosc 2016;30:4539-4543.

17. Kim SG, Moon JI, Choi IS, et al. Risk factors for conversion to conventional laparoscopic cholecystectomy in single incision laparoscopic cholecystectomy. Ann Surg Treat Res 2016;90:303-308.

18. Nassar AH, Ashkar KA, Rashed AA, Abdulmoneum MG. Laparoscopic cholecystectomy and the umbilicus. Br J Surg 1997;84:630-633.

19. Marks JM, Phillips MS, Tacchino R, et al. Single-incision laparoscopic cholecystectomy is associated with improved cosmesis scoring at the 
cost of significantly higher hernia rates: 1-year results of a prospective randomized, multicenter, single-blinded trial of traditional multiport laparoscopic cholecystectomy vs single-incision laparoscopic cholecystectomy. J Am Coll Surg 2013;216:1037-1048.

20. Gangl O, Hofer W, Tomaselli F, Sautner T, Függer R. Single incision laparoscopic cholecystectomy (SILC) versus laparoscopic cholecystectomy (LC)-a matched pair analysis. Langenbecks Arch Surg 2011;396:819-824.

21. Bunting DM. Port-site hernia following laparoscopic cholecystectomy. JSLS 2010;14:490-497.

22. Erdas E, Dazzi C, Secchi F, et al. Incidence and risk factors for trocar site hernia following laparoscopic cholecystectomy: a long-term follow-up study. Hernia 2012;16:431-437.

23. Markar SR, Karthikesalingam A, Thrumurthy S, Muirhead L, Kinross J, Paraskeva P. Single-incision laparoscopic surgery (SILS) vs. conventional multiport cholecystectomy: systematic review and metaanalysis. Surg Endosc 2012;26:1205-1213.

24. Rubay R, Hauters P, Valverde A, et al. Single umbilical incision laparoscopic cholecystectomy: results of the prospective trial of the Coelio Club. J Visc Surg 2012;149:417-420.

25. Flum DR, Horvath K, Koepsell T. Have outcomes of incisional hernia repair improved with time? A population-based analysis. Ann Surg 2003;237:129-135. 